\title{
Corrosion Resistance of Cordierite-Modified Light MMCs
}

\author{
A. Szewczyk-Nykiel, P. Długosz, P. Darłak, and M. Hebda
}

(Submitted November 12, 2016; in revised form April 17, 2017; published online May 2, 2017)

\begin{abstract}
Composites are one of the fastest developing materials. Research is particularly intensive in case of light metal alloys due to i.a. economic and environmental aspects. One of the innovative solutions is production of the metal matrix composites (MMC) by adding the cordierite ceramics obtained from fly ashes to magnesium alloys. In addition to obtaining new-generation materials with improved mechanical properties, also the waste is utilized which has a significant environmental and economic importance. In order to select the suitable operating conditions for such alloys, their corrosion resistance must be determined. This paper presents the results of corrosion resistance tests of AM60 magnesium alloy matrix composites reinforced with cordierite ceramics. The following issues were examined: (1) impact of the volume fraction of cordierite ceramics, 2 or 4 wt.\%; (2) impact of surface roughness (two variants of surface treatment); and (3) impact of heat treatment on corrosion resistance of obtained composites. The results were compared with data recorded for the base AM60 alloy (which surface treatment was identical as of the composites). Moreover, the XRD and microanalysis of the chemical compositions by EDS method were applied to determine phases occurring in the investigated composites. Furthermore, the XRD was also performed in order to identify the corrosion products on the surface of the material. The test results indicate that the alloy reinforced with $2 \mathrm{wt}$.\% addition of cordierite ceramics had the best corrosion resistance. It was also presented that surface and heat treatment affect the obtained results.
\end{abstract}

Keywords AM60 magnesium alloy, corrosion rates, electrochemical tests, metal matrix composites, surface roughness, squeeze casting, tafel slope

\section{Introduction}

Light metal alloys are now increasingly used as structural materials. Among them, magnesium-based materials possess particular properties, having low density and high specific strength. They also have a unique capability of damping vibration. On top of that, they have low inertia and because of that they can be used for making parts which rapidly accelerate or decelerate. For these reasons, intensive research is focusing i.a. on manufacturing magnesium-based metal matrix composites (MMC). As a result of advancements in manufacturing technologies, these materials find application in many industries such as automotive and aerospace (Ref 1-3).

One of the innovative solutions is production of the MMC by adding the cordierite ceramics obtained from fly ashes to magnesium alloys (Ref 4). In addition to obtaining newgeneration materials with improved mechanical properties, the waste is also utilized which has a significant environmental and economic importance. However, the mechanical strength of any material must be accompanied by corrosion resistance. By knowing the corrosion resistance, one can select the suitable operating conditions.

A. Szewczyk-Nykiel and M. Hebda, Institute of Materials Engineering, Cracow University of Technology, Warszawska 24, 31155 Kraków, Poland; and P. Długosz and P. Darlak, Foundry Research Institute, Zakopiańska 73, 30-418 Kraków, Poland. Contact e-mail: mhebda@pk.edu.pl.
It is generally known that magnesium has high chemical reactivity which leads to poor corrosion resistance. However, magnesium is resistant to atmospheric corrosion in a lowhumidity air due to forming an oxide layer on the surface. The durability and type of such layer depend on medium in which magnesium is present. On other hand, in a sea atmosphere the surface layer contains magnesium hydroxide and chloride which attract moisture due to hygroscopic properties of $\mathrm{MgCl}_{2}$. The magnesium impurities in acceptable amounts are cathodic, reducing the alloy's corrosion resistance.

The most popular magnesium alloys contain aluminum. According to Lounder (Ref 5) when the aluminum content in the alloy reaches $8 \mathrm{wt} . \%$, the corrosion resistance significantly increases. However, further research indicated that au much as 5 wt. $\%$ of $\mathrm{Al}$ content is sufficient to increase the corrosion resistance of $\mathrm{Mg}-\mathrm{Al}$ alloys ( $\mathrm{Ref} 6$ ). The corrosion resistance of magnesium alloys also depends considerably on volume fraction, size and distribution of $\beta$ phase $\left(\mathrm{Mg}_{17} \mathrm{Al}_{12}\right)$. Generally, it is believed that $\beta$ phase plays the role of a cathode in corrosion of magnesium alloys and has a passivating effect in a wide $\mathrm{pH}$ range. After dissolution of $\alpha$ phase - the matrix - $\beta$ phase can be the main corrosion inhibiting barrier. This barrier depends on the amount and distribution of $\beta$ phase. When the volume fraction of $\beta$ phase is large, the alloy grain size decreases and $\beta$ phase is distributed evenly in the alloy and the corrosion inhibiting barrier can be formed. However, when the grain size and the distance between the $\beta$ phase grains in the alloy increase, the alloy loses the corrosion resistance.

Zinc is also frequently added to magnesium alloys. The corrosion of such alloys is similar to the one occurring in magnesium alloys with addition of aluminum. The main reason of this effect is forming of galvanic microcells between the matrix and $\mathrm{MgZn}$ intermetallic compound. However, the difference of electric potentials between $\mathrm{MgZn}$ and the matrix is smaller than between $\mathrm{MgZn}$ and $\beta$ phase in alloys with addition of aluminum. As a result, at correctly chosen zinc 
content and microstructure such materials can have better corrosion resistance than the alloys containing aluminum (Ref 7).

Another factor affecting the corrosion resistance of magnesium alloys (albeit to a significantly lesser extent) is grain size. Grain boundaries are one of the factors which allows explain the increase in corrosion resistance with decreasing of grain size. However, Song et al. (Ref 8 ) proved that boundaries are not a barrier in corrosion growth and are more chemically active than grains. Another hypothesis which explains why corrosion resistance increases when the grain size decreases is compensation of stress formed on the boundary between $\mathrm{MgO}$ and $\mathrm{Mg}$. The oxide layer on the surface of a fine-grained alloy has a better coverage of metal and less cracking. Hence, the metal has an increased stability of the passive layer (Ref 9 ). It is well known that the addition of $\mathrm{Cu}, \mathrm{Fe}$ or $\mathrm{Ni}$ is limited in magnesium alloys because they increase the susceptibility to corrosion by forming cathodic compounds.

Furthermore, heat treatment is used to obtain an adequate microstructure of magnesium alloys. If treatment is carried out at temperatures above $300{ }^{\circ} \mathrm{C}$, a protective atmosphere is used. The treatment of magnesium alloys usually involves solution heat treatment and aging. This significantly improves strength properties, plasticity and hardness of the alloy, with a slight decrease in elongation.

This paper presents the results of corrosion resistance tests of MMC made off AM60 magnesium alloy modified with the addition of cordierite ceramics. The following issues were examined: (1) impact of the volume fraction of cordierite, 2 or 4 wt.\%; (2) impact of surface roughness (two variants of surface treatment); and (3) impact of heat treatment on corrosion resistance of obtained composites. The results were compared with results recorded for the base AM60 alloy which surface treatment was identical as of the composites. Moreover, the XRD and microanalysis of the chemical compositions by EDS method were applied to determine phases occurring in the investigated composites. Furthermore, the XRD was also performed in order to identify the corrosion products on the surface of the material.

\section{Materials and Methods}

Commonly used casting alloy, the AM60 magnesium alloy, was selected as the metal matrix for the composites. The chemical composition of the alloys is shown in Table 1. The reinforcing material was cordierite ceramics $\left(\mathrm{Mg}_{2} \mathrm{Al}_{4} \mathrm{Si}_{5} \mathrm{O}_{18}\right)$ manufactured by synthesis of fly ash. The chemical composition is shown in Table 2.

Cordierite ceramics was introduced into the matrix at 2 and $4 \mathrm{wt} . \%$ as a powder produced by grinding in a high-power ball mill at $1800 \mathrm{rpm}$ for $2 \mathrm{~h}$. The MMCs were manufactured at ca. $50{ }^{\circ} \mathrm{C}$ above the matrix melting point in the vortex process. The samples were squeeze-casted into a dia. $200 \mathrm{~mm}$ cylindrical mold at the press force of 160 tons. The reference materials selected for the experiments were MMC samples without cordierite, i.e., made of the base alloys (see Table 1) with the identical process.

The heat treatment was performed on composites and on the AM60 base alloy. The materials were solution heat-treated at $410{ }^{\circ} \mathrm{C}$ for $24 \mathrm{~h}$. The aging process was conducted at $200{ }^{\circ} \mathrm{C}$ for $12 \mathrm{~h}$. In both cases, the heating and cooling rates were $10{ }^{\circ} \mathrm{C} / \mathrm{min}$.

In order to estimate the influence of heat treatment on corrosion resistance of AM60 and AM60 matrix composites reinforced with cordierite ceramics, the electrochemical test was performed on samples of studied materials after heat treatment as well as without it. The corrosion tests were performed on cylindrical specimens with diameter $20 \mathrm{~cm}$ and $5 \mathrm{~mm}$ high. Furthermore, the working electrode was appropriately prepared before electrochemical tests. Namely, the surface of sample was successively polished with 600-grit (A series of samples) or 2000-grit (B series of samples) carborundum abrasive paper, then degreased with acetone, rinsed with distilled water and finally dried.

Designation of specimens used in the tests, depending on their chemical composition and preparation-heat and surface treatment, is presented in Table 3.

The electrochemical tests, i.e., open circuit potential (OCP) variation with time and potentiodynamic polarization, were performed using ATLAS 0531 UI\&IA potentiostat cooperating with AtlasCorr05 software. Measurements were taken in environment of a $3.5 \% \mathrm{NaCl}$ solution at ambient temperature. A conventional three-electrode electrochemical cell was utilized. The saturated calomel electrode (SCE) was used as reference electrode. Platinum electrode was working as a counter electrode. The specimen was a working electrode. The exposed area was $1.33 \mathrm{~cm}^{2}$. It is known that the open circuit potential can be used as a criterion for the corrosion behavior. OCP indicates the thermodynamic tendency of a material to electrochemical oxidation in a corrosive environment. This potential may vary with time of immersion. This happens due to changes occurring in the nature of the surface of the electrode (oxidation, formation of the passive layer or immunity). After a certain time of immersion, the potential stabilizes around a steady value. The corrosion test started with the open circuit potential measurement. The potential of the samples was recorded and monitored in a function of immersion time until it reached a stationary value. Open circuit potential (OCP) was measured over $1 \mathrm{~h}$ of immersion in solution. After the OCP measurement, the potentiodynamic polarization test was performed. The potential was increased at a rate of $1 \mathrm{mV} / \mathrm{s}$, starting from about $250 \mathrm{mV}$ below the OCP and increase up to about $1.1 \mathrm{~V}$. The potentiodynamic polarization measurements were taken in order to evaluate the corrosion parameters such as corrosion potential (Ecorr), corrosion current density (Icorr), cathodic $\left(B_{\mathrm{c}}\right)$ and anodic $\left(B_{\mathrm{a}}\right)$ Tafel slope, polarization resistance $(R \mathrm{pol})$ and corrosion rate $(\mathrm{CR})$. The polarization resistance was determined using linear polarization method (called

Table 1 Chemical composition of the AM60 magnesium alloy

\begin{tabular}{|c|c|c|c|c|c|c|c|c|}
\hline \multirow[b]{2}{*}{ Designation } & \multicolumn{8}{|c|}{ Chemical composition, wt.\% } \\
\hline & Si & $\mathbf{C u}$ & Mg & Mn & $\mathbf{F e}$ & $\mathbf{T i}$ & Zn & Al \\
\hline AM60 & Max 0.5 & Max 0.35 & balance & $0.13-0.6$ & $\ldots$ & $\ldots$ & 0.22 & $5.5-6.5$ \\
\hline
\end{tabular}


Table 2 Chemical composition of the cordierite ceramics

\begin{tabular}{lccccccc}
\hline & \multicolumn{7}{c}{ Chemical composition, wt.\% } \\
\cline { 2 - 7 } Designation & $\mathbf{S i O}_{\mathbf{2}}$ & $\mathbf{A l}_{\mathbf{2}} \mathbf{O}_{\mathbf{3}}$ & $\mathbf{F e O}_{\mathbf{3}}$ & $\mathbf{M g O}$ & $\mathbf{C a O}$ & $\mathbf{N a}_{2} \mathbf{O}$ & $\mathbf{H}_{\mathbf{2}} \mathbf{O}$ \\
\hline Cordierite ceramics & $45-51$ & $32-35$ & $2-12$ & $3-35$ & $\operatorname{Max} 3$ & Max 3 & Max 3 \\
\hline
\end{tabular}

Table 3 Designation of specimens depending on chemical composition and preparation

\begin{tabular}{|c|c|c|c|c|}
\hline \multirow{2}{*}{$\begin{array}{l}\text { Heat } \\
\text { treatment }\end{array}$} & \multicolumn{2}{|c|}{ A series polished with 600 -grit abrasive paper } & \multicolumn{2}{|c|}{ B series polished with 2000 -grit abrasive paper } \\
\hline & Material & Designation & Material & Designation \\
\hline \multirow[t]{3}{*}{ No } & AM60 alloy & AM60 600 & AM60 alloy & AM60 2000 \\
\hline & $\begin{array}{l}\text { AM60 with } 2 \text { wt. } \% \text { of cordierite } \\
\text { ceramics addition }\end{array}$ & AM60 2C 600 & $\begin{array}{l}\text { AM60 with } 2 \text { wt. } \% \text { of cordierite } \\
\text { ceramics addition }\end{array}$ & AM60 2C 2000 \\
\hline & $\begin{array}{l}\text { AM60 with } 4 \text { wt. } \% \text { of cordierite } \\
\text { ceramics addition }\end{array}$ & AM60 4C 600 & $\begin{array}{l}\text { AM60 with } 4 \text { wt. } \% \text { of cordierite } \\
\text { ceramics addition }\end{array}$ & AM60 4C 2000 \\
\hline \multirow[t]{3}{*}{ Yes } & AM60 alloy & AM60 $600 \mathrm{HT}$ & AM60 alloy & AM60 $2000 \mathrm{HT}$ \\
\hline & $\begin{array}{l}\text { AM60 with } 2 \text { wt. } \% \text { of cordierite } \\
\text { ceramics addition }\end{array}$ & AM60 2C $600 \mathrm{HT}$ & $\begin{array}{l}\text { AM60 with } 2 \text { wt. } \% \text { of cordierite } \\
\text { ceramics addition }\end{array}$ & AM60 2C $2000 \mathrm{HT}$ \\
\hline & $\begin{array}{l}\text { AM60 with } 4 \text { wt. } \% \text { of cordierite } \\
\text { ceramics addition }\end{array}$ & AM60 4C $600 \mathrm{HT}$ & $\begin{array}{l}\text { AM60 with } 4 \text { wt. } \% \text { of cordierite } \\
\text { ceramics addition }\end{array}$ & AM60 4C $2000 \mathrm{HT}$ \\
\hline
\end{tabular}

Stern method) and Tafel extrapolate method (called SternGeary method). The corrosion rate, in terms of penetration rate (CR) and mass loss rate (MR), was calculated according to ASTM G102 (Standard Practice for Calculation of Corrosion Rates and Related Information from Electrochemical Measurements).

The microstructure was examined using the JSM5510LV scanning microscope. Microanalysis of the chemical compositions of phases occurring in the investigated composites was checked using an energy-dispersive spectrometer (EDS), IXRF Systems Model 500 Digital Processing.

The phase identification was performed by an x-ray diffraction apparatus D2 Phaser analyzer manufactured by Bruker (anode: $\mathrm{Cu}$ (copper); step of measurement: $0.02^{\circ} ; 8 \mathrm{~s}$. per step). The main phases were identified by means of the measurement of interplanar distances and the subsequent comparison of the obtained set of data with the pattern set. Diffraction data processing was performed with Evasoftware. The phases were identified with PDF2 database.

\section{Results and Discussion}

A comparison of microstructure of composites with AM60 base alloy indicates the presence of an additional phase. The phase with oval shapes, which often join one another, occurred in all analyzed specimens (with and without cordierite ceramics). The additional phase, on the other hand, had linear forms which intersected each other, usually at angles close to $90^{\circ}$. This phase was noticed only in materials containing cordierite. In addition, it was observed that the volume fraction of this phase increased when amount of cordierite ceramics added to the composite also increased.

A representative microstructure of the AM60 composite with 2 wt. $\%$ of cordierite ceramics is shown in Fig. 1. Precipitates of two additional phases in the alloy matrix can be clearly seen. The XRD (Fig. 2) confirmed that the first phase was $\mathrm{Mg}_{17} \mathrm{Al}_{12}$, and another one was $\mathrm{Mg}_{2} \mathrm{Si}$. Moreover, the

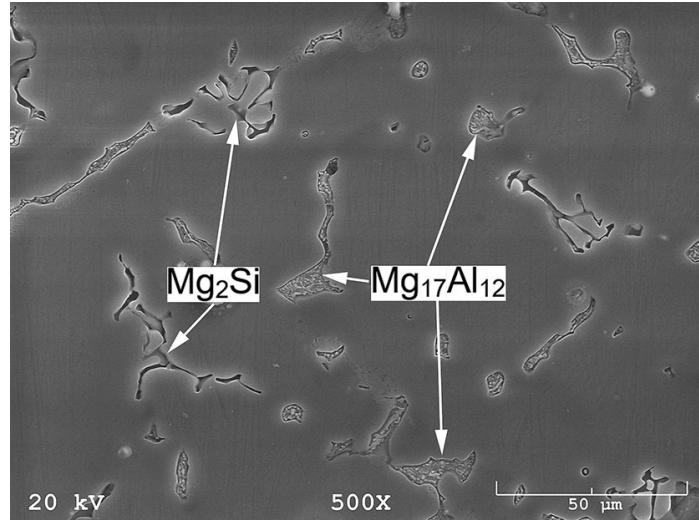

Fig. 1 Microstructure of AM60 composite reinforced with 2 wt.\% of cordierite ceramics

chemical compositions of phases identified by EDS method are shown in Table 4. Furthermore, the specific phase morphology in the form of coarse Chinese script shape additionally proves the presence of $\mathrm{Mg}_{2} \mathrm{Si}$ phase (Ref 4, 10-13). It was also observed that the heat treatment did not affect significantly the microstructure of tested composites.

It was stated that corrosion resistance of magnesium alloys is affected by some factors, such as chemical composition, the nature of the aggressive environment, quality of sample surface and heat treatment (Ref 14, 15).

The variations in open circuit potential for all investigated materials immersed in $3.5 \% \mathrm{NaCl}$ solution were monitored. The selected results are presented in Fig. 3, 4 and 5. The values of open circuit potential at the beginning of the test and after $1 \mathrm{~h}$ of immersion were determined and they are listed in Tables 5 and 6 .

It can be stated that the values of open circuit potential at the beginning of test are lower in comparison with OCP after $1 \mathrm{~h}$ of immersion in $3.5 \% \mathrm{NaCl}$ solution for all investigated materials. In case of all investigated materials, displacement of the OCP 


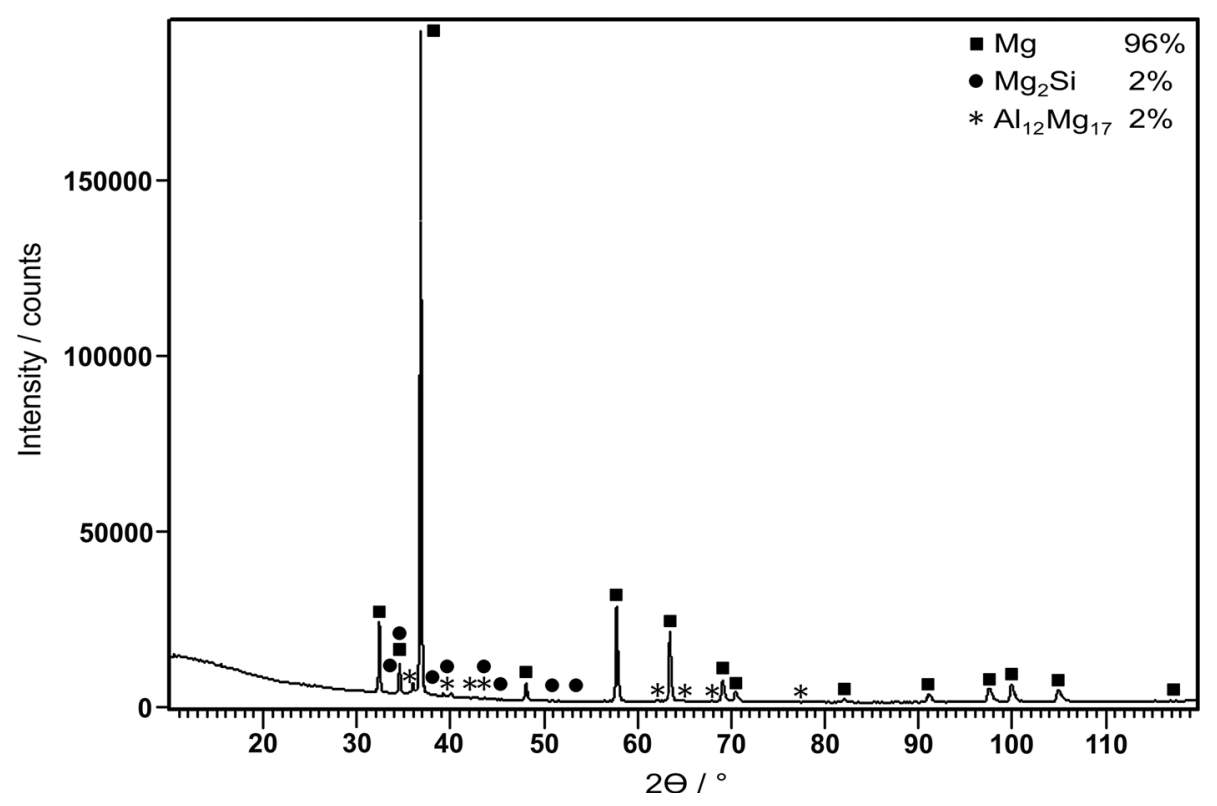

Fig. 2 XRD pattern for AM60 composite reinforced with 2 wt.\% of cordierite ceramics

Table 4 Microanalysis of the chemical compositions of phases observed in Fig. 1

\begin{tabular}{lccc}
\hline & \multicolumn{3}{c}{ Chemical composition, wt.\% } \\
\cline { 2 - 4 } Phase & $\mathbf{M g}$ & Al & $\mathbf{S i}$ \\
\hline $\mathrm{Mg}_{17} \mathrm{Al}_{12}$ & $69.55 \pm 0.43$ & $30.45 \pm 0.37$ & 0 \\
$\mathrm{Mg}_{2} \mathrm{Si}$ & $64.58 \pm 0.48$ & 0 & $35.42 \pm 0.44$ \\
\hline
\end{tabular}

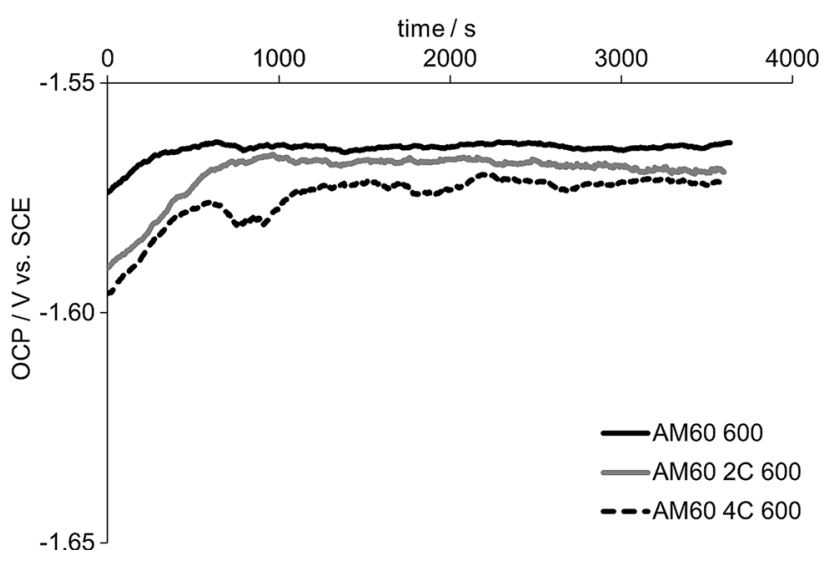

Fig. 3 Variation in open circuit potential with time for selected investigated materials without heat treatment

toward positive values can be seen. The increase in OCP indicates noble metal behavior. This effect was caused by changes taking place in the surface of material. The formation of the oxide film on the sample surface occurred. This kind of behavior improves corrosion resistance. The OCP of AM60 alloy reaches steady values after a period of about $1000 \mathrm{~s}$. In case of AM60 matrix composites, this period is longer, about $2000 \mathrm{~s}$ than for AM60 with 4 wt.\% of cordierite ceramics composites. The constant value of OCP suggests the thermodynamic stability of the passive layer and resistance to chemical

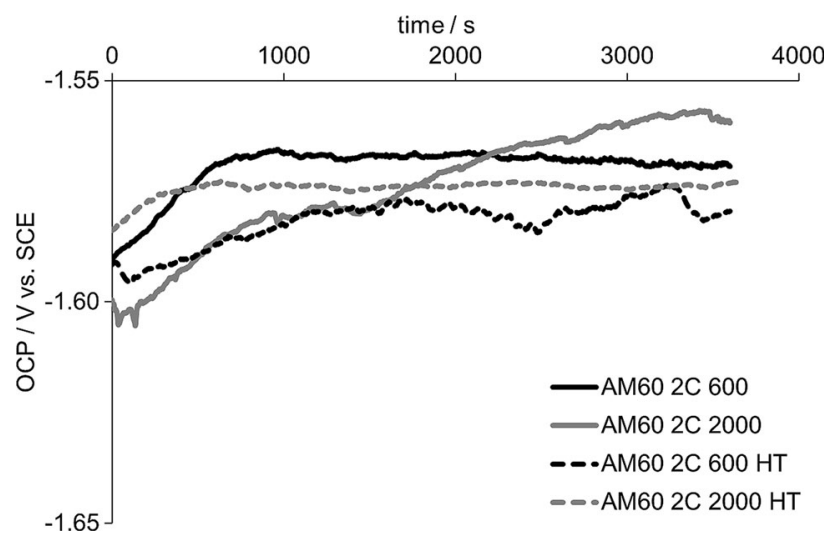

Fig. 4 Variation in open circuit potential with time for AM60 magnesium alloy matrix composites reinforced with $2 \mathrm{wt} . \%$ of cordierite ceramics

dissolution in $3.5 \% \mathrm{NaCl}$ solution. Moreover, the impact of heat treatment on corrosion behavior of magnesium alloys and composites was observed (Fig. 4 and 5). The OCP for heattreated AM60 alloy as well as AM60 matrix composites shows the tendency to shift toward more negative direction, consequently the values are lower. The obtained results indicate that in the A series specimens (designation according to Table 3) the OCP decreased with increasing content of cordierite ceramics in the alloy. In all of the B series specimens, it was the other way around: the OCP increased with increasing content of cordierite ceramics in the alloy. This effect was independent of heat treatment. The observed relationships confirm the impact of the surface treatment (surface roughness) on corrosion processes occurring during the measurements.

A few literature references from other researchers also prove that surface roughness of magnesium alloys rather significantly affects their corrosion behavior. For instance, Alvare et al. (Ref 16) found that in case of AE44 alloy, the increased surface 


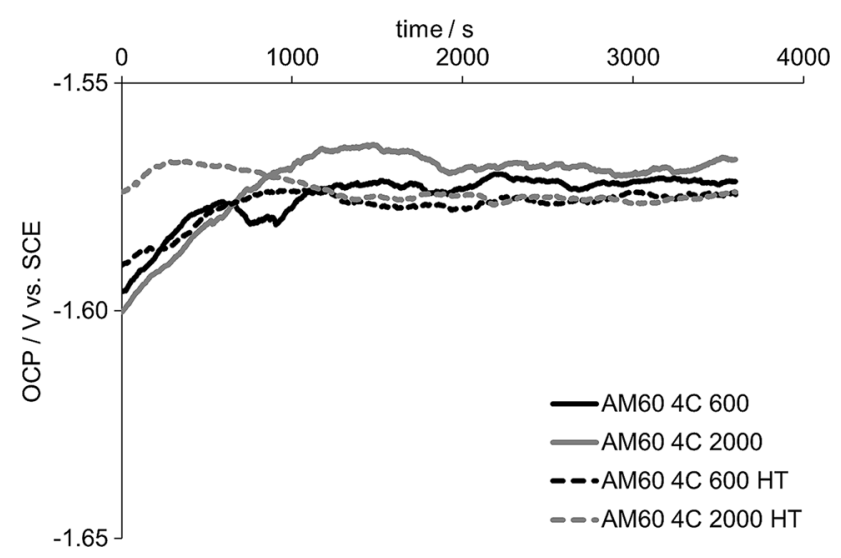

Fig. 5 Variation in open circuit potential with time for AM60 magnesium alloy matrix composites reinforced with $4 \mathrm{wt} . \%$ of cordierite ceramics

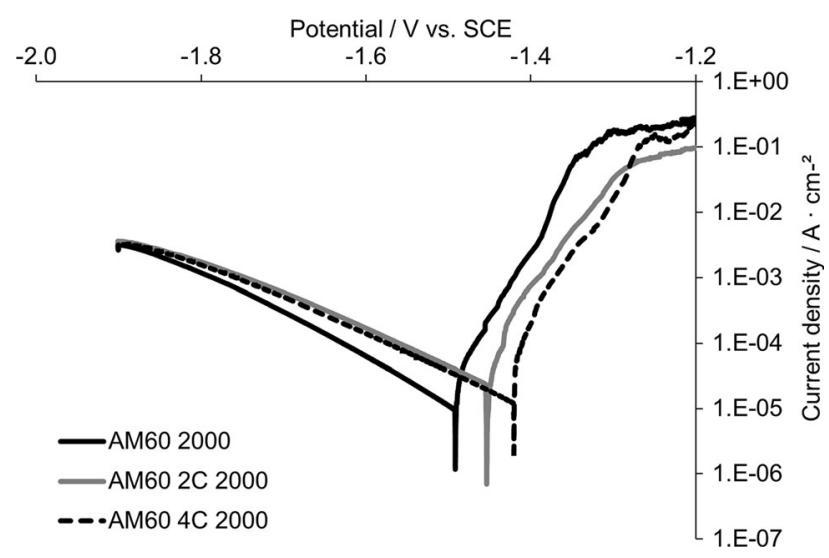

Fig. 6 Potentiodynamic polarization curves of AM60 magnesium alloy and AM60 matrix composites reinforced with cordierite ceramics (B series, without heat treatment)

Table 5 The values of open circuit potential: at the beginning and after $1 \mathrm{~h}$ of immersion in $3.5 \% \mathrm{NaCl}$ solution for AM60 magnesium alloy as well as magnesium alloy matrix composites reinforced with cordierite ceramics in an amount of 2 and 4 wt. $\%$

\begin{tabular}{lcccccc}
\hline & \multicolumn{5}{c}{ Designation } \\
\cline { 2 - 6 } OCP, V vs. SCE & AM60 600 & AM60 2C 600 & AM60 4C 600 & AM60 2000 & AM60 2C 2000 & AM60 4C 2000 \\
\hline Initially & -1.574 & -1.590 & -1.596 & -1.592 & -1.600 & -1.600 \\
After 1 h & -1.564 & -1.569 & -1.572 & -1.571 & -1.569 & -1.559 \\
\hline
\end{tabular}

Table 6 The values of open circuit potential at the beginning and after $1 \mathrm{~h}$ of immersion in $3.5 \% \mathrm{NaCl}$ solution for heattreated AM60 magnesium alloy as well as magnesium alloy matrix composites reinforced with cordierite ceramics in an amount of 2 and 4 wt.\%

Designation

OCP, V vs. SCE AM60 600 HT AM60 2C 600 HT AM60 4C 600 HT AM60 2000 HT AM60 2C 2000 HT AM60 4C 2000 HT

\begin{tabular}{llllll}
\hline Initially & & & & & \\
After $1 \mathrm{~h}$ & -1.577 & -1.592 & -1.590 & -1.579 & -1.584 \\
\end{tabular}

roughness reduces the total corrosion of the alloy during the immersion test in $3.5 \% \mathrm{NaCl}$. In addition, the specimens with the smallest surface roughness showed greater pitting corrosion and greater volume of pits in the material in comparison with the specimens with higher roughness.

On the other hand, Walter et al. (Ref 14) studied the AZ91 alloy. The surfaces of specimens were ground with 320-, 600and 1200-grit abrasive paper and polished using 3- $\mu \mathrm{m}$ diamond paste. The measurements indicated that in immersion tests in $0.5 \% \mathrm{NaCl}$ for $24 \mathrm{~h}$, the specimens with the smallest surface roughness had the best corrosion resistance. The specimen with the highest surface roughness succumbed to pitting corrosion to a rather significant degree. The analogous measurements performed with the use of a galvanostat gave opposite results to measurements during the immersion tests. It was observed that increased surface smoothness resulted in an increased number of corrosion pits. These tests proved that, past the passivation barrier, surface roughness has a significant impact on the occurrence of corrosion pits. The selected polarization curves of AM60 magnesium alloy and AM60 matrix composites reinforced with cordierite ceramics are shown in Fig. 6 and 7.

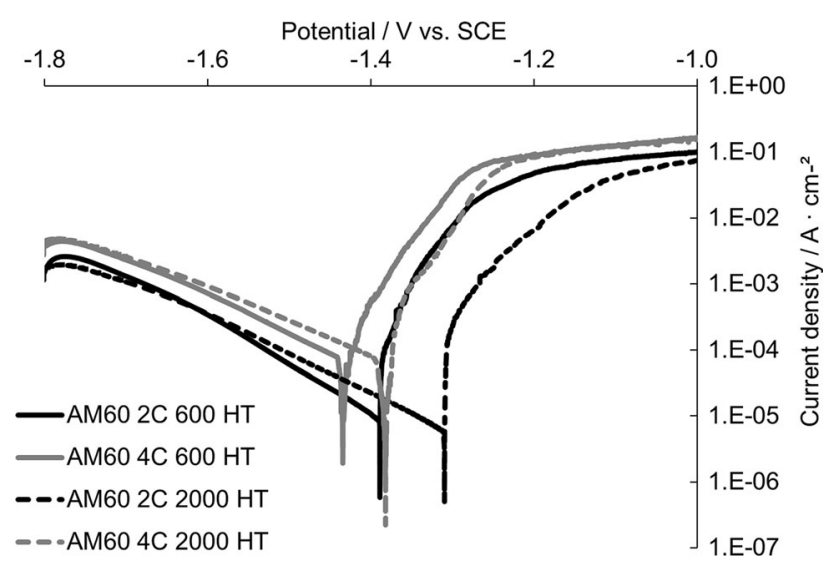

Fig. 7 Potentiodynamic polarization curves of heat-treated AM60 matrix composites reinforced with cordierite ceramics

As it can be seen from presented potentiodynamic polarization curves, there is no symmetry between anodic and cathodic branches of polarization curves. Practically, each of 
Table 7 Corrosion parameters for AM60 magnesium alloy as well as AM60 matrix composites reinforced with cordierite ceramics in an amount of 2 and $4 \mathrm{wt} . \%$

Designation

\begin{tabular}{|c|c|c|c|c|c|c|}
\hline & \multicolumn{6}{|c|}{ Designation } \\
\hline & AM60 600 HT & AM60 2C 600 HT & AM60 4C 600 HT & AM60 2000 HT & AM60 2C 2000 HT & AM60 4C 2000 HT \\
\hline$E_{\text {corr, }}, \mathrm{V}$ vs. SCE & -1.429 & -1.470 & -1.472 & -1.492 & -1.454 & -1.421 \\
\hline$I_{\text {corr }}, \mathrm{A} \mathrm{cm}^{-2}$ & $7.01 \mathrm{E}-05$ & $5.77 \mathrm{E}-05$ & $6.31 \mathrm{E}-05$ & $1.00 \mathrm{E}-05$ & $2.47 \mathrm{E}-05$ & $1.25 \mathrm{E}-05$ \\
\hline$R_{\mathrm{pol}}(\mathrm{a}), \Omega \mathrm{cm}^{2}$ & 48.14 & 247.69 & 64.78 & 251.68 & 119.68 & 122.37 \\
\hline$R_{\mathrm{pol}}(\mathrm{b}), \Omega \mathrm{cm}^{2}$ & 96.33 & 282.75 & 109.16 & 291.13 & 150.87 & 152.58 \\
\hline$B_{\mathrm{a},}, \mathrm{V}$ & 0.017 & 0.047 & 0.017 & 0.007 & 0.009 & 0.005 \\
\hline$B_{\mathrm{c}}, \mathrm{V}$ & 0.185 & 0.184 & 0.200 & 0.132 & 0.174 & 0.167 \\
\hline $\mathrm{CR}, \mathrm{mm} / \mathrm{yr}$ & 1.50 & 1.22 & 1.33 & 0.21 & 0.52 & 0.26 \\
\hline MR, $g / \mathrm{m}^{2} \mathrm{~d}$ & 7.50 & 6.17 & 6.75 & 1.07 & 2.64 & 1.34 \\
\hline
\end{tabular}

Table 8 Corrosion parameters for heat-treated AM60 magnesium alloy as well as AM60 matrix composites reinforced with cordierite ceramics in an amount of 2 and 4 wt.\%

\begin{tabular}{|c|c|c|c|c|c|c|}
\hline & \multicolumn{6}{|c|}{ Designation } \\
\hline & AM60 600 HT & AM60 2C 600 HT & AM60 4C 600 HT & AM60 2000 HT & AM60 2C 2000 HT & AM60 4C 2000 HT \\
\hline$E_{\text {corr, }}, \mathrm{V}$ vs. SCE & -1.478 & -1.389 & -1.435 & -1.373 & -1.310 & -1.382 \\
\hline$I_{\text {corr, }} \mathrm{A} \mathrm{cm}^{-2}$ & $8.82 \mathrm{E}-05$ & $8.84 \mathrm{E}-06$ & $6.90 \mathrm{E}-05$ & $3.30 \mathrm{E}-06$ & $5.83 \mathrm{E}-06$ & $6.56 \mathrm{E}-05$ \\
\hline$R_{\mathrm{pol}}(\mathrm{a}), \Omega \mathrm{cm}^{2}$ & 193.84 & 298.83 & 163.92 & 95.95 & 178.03 & 173.58 \\
\hline$R_{\mathrm{pol}}(\mathrm{b}), \Omega \mathrm{cm}^{2}$ & 178.13 & 367.80 & 222.58 & 93.41 & 118.89 & 131.63 \\
\hline$B_{\mathrm{a}}, \mathrm{V}$ & 0.061 & 0.008 & 0.045 & 0.001 & 0.002 & 0.022 \\
\hline$B_{\mathrm{c}}, \mathrm{V}$ & 0.090 & 0.132 & 0.162 & 0.127 & 0.160 & 0.189 \\
\hline $\mathrm{CR}, \mathrm{mm} / \mathrm{yr}$ & 1.88 & 0.19 & 1.45 & 0.07 & 0.12 & 1.38 \\
\hline $\mathrm{MR}, \mathrm{g} / \mathrm{m}^{2} \mathrm{~d}$ & 9.43 & 0.94 & 7.37 & 0.35 & 0.62 & 7.01 \\
\hline
\end{tabular}

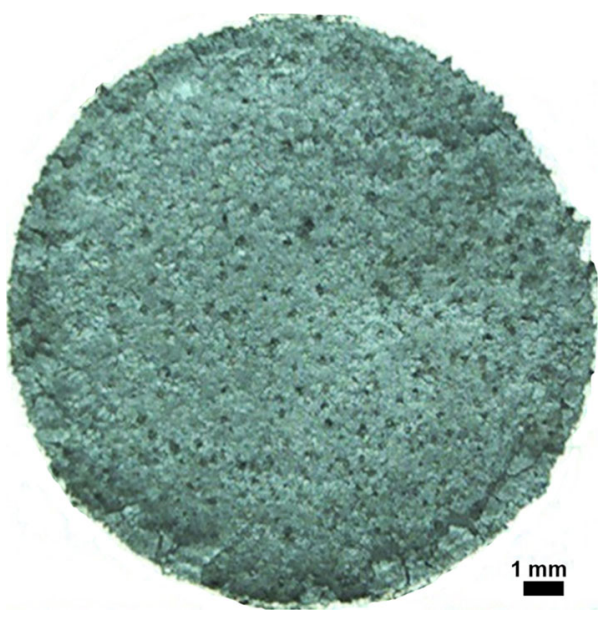

Fig. 8 Macrostructure of AM60 2000 HT specimen after potentiodynamic tests

the curves exhibits the linear behavior almost to the value of the corrosion potential, while anodic branches show sharper changes in comparison with the cathodic branches. The corrosion parameters such as corrosion potential $\left(E_{\text {corr }}\right)$, corrosion current density $\left(I_{\text {corr }}\right)$, anodic $\left(B_{\mathrm{a}}\right)$ and cathodic $\left(B_{\mathrm{c}}\right)$ Tafel constants, polarization resistance $\left(R_{\mathrm{pol}}\right)$ evaluated based on polarization curves as well as corrosion rate (CR)

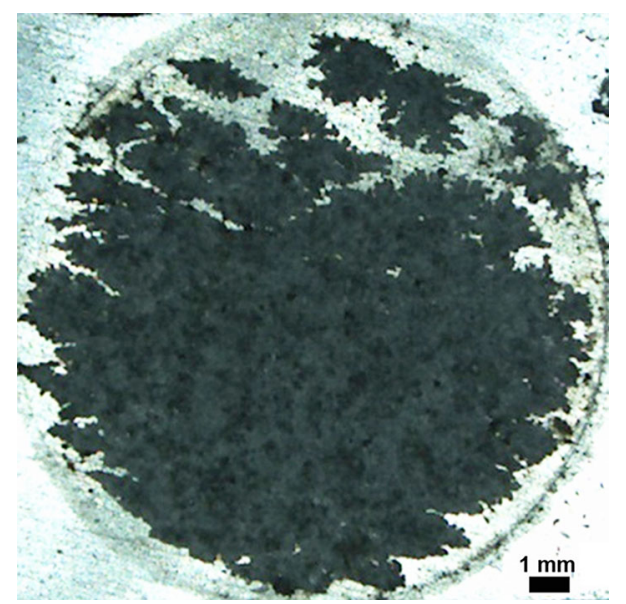

Fig. 9 Macrostructure of AM60 2C 600 HT specimen after potentiodynamic tests

have been calculated for all investigated materials. They are listed in Tables 7 and 8 . The polarization resistance was determined using Stern method as well as Stern-Geary method.

As expected, the conditions of sample preparation affected the parameters such as corrosion potential, corrosion current density as well as corrosion rate. 


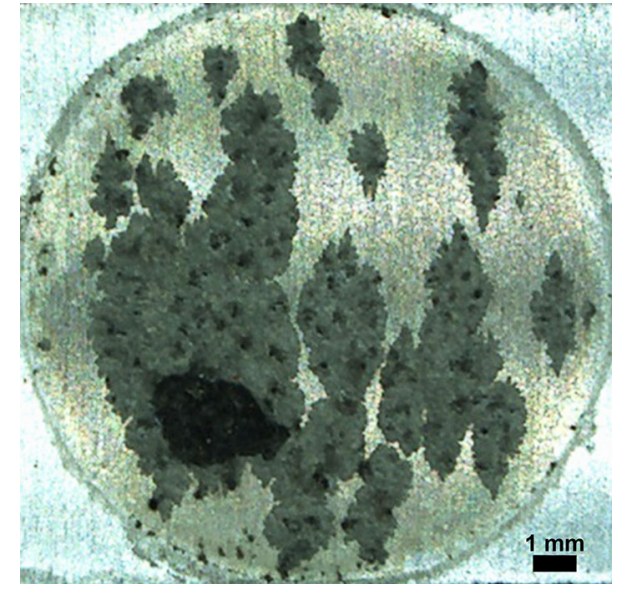

Fig. 10 Macrostructure of AM60 2C 2000 HT specimen after potentiodynamic tests

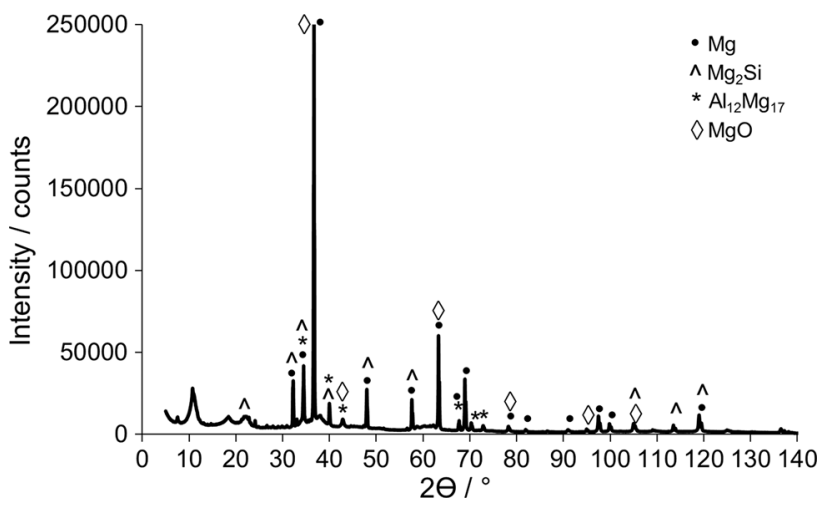

Fig. 11 XRD pattern of AM60 4C 600 HT specimen after potentiodynamic measurements

Samples from the B series exhibit lower values of corrosion current density and higher values of potential corrosion and corrosion rate (CR and MR) in comparison with similarly prepared samples from the series A. Moreover, the increase in corrosion potential and polarization resistance was observed, while current density, corrosion rate as well as anodic and cathodic Tafel decreased constantly for heat-treated AM60 reinforced with $2 \mathrm{wt} . \%$ of cordierite ceramics. It can be said that only for composites with this chemical composition the heat treatment significantly improves the corrosion resistance. It should be emphasized that this material has the best corrosion resistance among all of the investigated materials. The corrosion processes occurring in composites can be explained as follows.

The corrosion properties of magnesium alloy result from its high chemical activity and the contents of precipitates. Phase $\mathrm{Mg}_{17} \mathrm{Al}_{12}$ exists in the microstructure of AM60 magnesium alloy. The value of potential corrosion of the $\mathrm{Mg}_{17} \mathrm{Al}_{12}$ phase is $-1.20 \mathrm{~V}$ versus SCE (Ref 17). This phase is more resistant to corrosion in comparison with $\alpha-\mathrm{Mg}$ matrix. It is generally believed that this phase acts as a cathode in case of magnesium alloys corrosion and it exhibits a good passive behavior. After immersion of the magnesium alloy in $3.5 \% \mathrm{NaCl}$ solution, the formation of an electrolytic cell occurs. The $\mathrm{Mg}_{17} \mathrm{Al}_{12}$ phase is the cathode and the surrounding matrix is the anode. According to the studies (Ref 7, 17), after the dissolution of the anodic $\alpha$ phase, $\mathrm{Mg}_{17} \mathrm{Al}_{12}$ may play the role of a barrier to inhibit corrosion.

After exposure to chloride ions in a non-oxidizing medium, pitting corrosion will occur at free corrosion potential of magnesium. It is generally observed that corrosion pits initiate at the secondary phase such as $\mathrm{Mg}_{17} \mathrm{Al}_{12}$ as a result of the breakdown of passivity.

The corrosion reactions of magnesium alloy can be expressed as:

$$
\mathrm{Mg}+2 \mathrm{H}_{2} \mathrm{O} \rightarrow \mathrm{Mg}(\mathrm{OH})_{2}+\mathrm{H}_{2}
$$

Oxygen reduction as per following reaction:

$$
\mathrm{H}_{2} \mathrm{O}+\frac{1}{2} \mathrm{O}_{2}+2 \mathrm{e}^{-} \rightarrow 2 \mathrm{OH}^{-}
$$

is a main cathodic reaction. The hydrolysis reaction starts corrosion. The oxidation of $\mathrm{Mg}$ as $\mathrm{Mg}_{2}+\left(\mathrm{Mg}+2 \mathrm{e}^{-} \rightarrow \mathrm{Mg}_{2}^{+}\right)$ proceeds by the reaction $\mathrm{Mg}_{2}^{+}+2 \mathrm{OH}^{-} \rightarrow \mathrm{Mg}(\mathrm{OH})_{2}$.

This results in the formation of $\mathrm{Mg}(\mathrm{OH})_{2}$ precipitates at the magnesium alloy surfaces.

Representative photographs of macrostructures of areas following the potentiodynamic tests for AM60 alloy and composites containing $2 \mathrm{wt} \%$ of cordierite ceramics are presented in Fig. 8, 9 and 10.

The presented surfaces show the effects of potentiodynamic tests. The whole surface of the AM60 alloy was covered with corrosion products. However, the formed layer did not protect the material from further damage. The specimen underwent further pitting corrosion.

The smallest amount of corrosion products in the form of isolated precipitates was observed for composite with $2 \mathrm{wt} . \%$ addition of cordierite ceramics and polished with 2000-grid abrasive paper. A similar trend was also observed in case of AM60 alloy without and with 4 wt.\% addition of cordierite ceramics.

In order to identify the corrosion products formed on surface of composites, the XRD analysis was performed after the potentiodynamic measurements. The diffraction pattern of AM60 4C 600 HT specimen is presented in Fig. 11. The results indicate that the magnesium oxide phase precipitates on the surface of the material. Similar effect was reported by Ma et al. (Ref 18).

\section{Conclusions}

A novel magnesium alloy matrix composites reinforced with cordierite ceramics, obtained from fly ashes and produced by squeeze casting were investigated. In this study, comprehensive analysis concerning the corrosion resistance was demonstrated.

On the basis of the obtained results, it was found that both surface roughness and volume fraction of cordierite ceramics in AM60 alloy have a significant impact on the corrosion resistance of obtained composites. The heat treatment has a smaller impact on the material properties. The corrosion resistance increased with decreasing of surface roughness. The AM60 magnesium alloy matrix composites reinforced with $2 \mathrm{wt} . \%$ addition of cordierite ceramics had the best corrosion resistance. Moreover, the investigated magnesium composites 
can be an alternative for aluminum composites which find application in many industries such as automotive or aerospace. In particular, they may be used for the production of parts that must have increased resistance to corrosion.

\section{Open Access}

This article is distributed under the terms of the Creative Commons Attribution 4.0 International License (http:// creativecommons.org/licenses/by/4.0/), which permits unrestricted use, distribution, and reproduction in any medium, provided you give appropriate credit to the original author(s) and the source, provide a link to the Creative Commons license, and indicate if changes were made.

\section{References}

1. A.A. Luo, Applications: Aerospace, Automotive and Other Structural Applications of Magnesium, Fundam. Magn. Alloy Metall., 2013. doi: 10.1533/9780857097293.266

2. A.A. Luo, and A.K. Sachdev, Applications of Magnesium Alloys in Automotive Engineering, Adv. Wrought Magn. Alloys, 2012. doi: 10.1016/B978-1-84569-968-0.50012-0

3. D.K. Koli, G. Agnihotri, and R. Purohit, Advanced Aluminium Matrix Composites: The Critical Need of Automotive and Aerospace Engineering Fields, Mater. Today, 2015, 2(4-5), p 3032-3041

4. P. Długosz, A. Rączka, A. Kopeć, R. Krzyżak, P. Darłak, and M. Hebda, Properties of Light MMCS Modified with Cordierite Synthesized from Fly Ash, J. Mater. Eng. Perform., 2016, 25(6), p 2261-2266

5. O. Lunder, J.E. Lein, T.K. Aune, and K. Nisancioglu, The Role of Magnesium Aluminium $\left(\mathrm{Mg}_{17} \mathrm{Al}_{12}\right)$ Phase in the Corrosion of Magnesium Alloy AZ91, Corrosion, 1989, 45, p 741-748

6. T.J. Warner, N.A. Thorne, G. Nussbaum, and W.M. Stobbs, Across Sectional Tem Study of Corrosion Initiation in Rapidly Solidified
Magnesium-Based Ribbon, Surf. Interface Anal., 1992, 19, p 386392

7. Ch Ying-Liang, Q. Ting-Wei, W. Hui-Min, and Z. Zhao, Comparison of Corrosion Behaviors of AZ31, AZ91, AM60 and ZK60 Magnesium Alloys, Trans. Nonferrous Met. Soc. China, 2009, 19, p 517-524

8. G. Song and Z. Xu, Effect of Microstructure Evolution on Corrosion of Different Crystal Surfaces of AZ31 Mg Alloy in a Chloride Containing Solution, Corros. Sci., 2012, 54, p 97-105

9. L. Jinsun, H. Makota, and Y. Naotsugu, Corrosion Behaviour of FineGrained AZ31 B Magnesium Alloy, Corros. Sci., 2012, 61, p 208-214

10. C. Rauber, A. Lohmüller, S. Opel, and R.F. Singer, Microstructure and Mechanical Properties of SiC Particle Reinforced Magnesium Composites Processed by Injection Molding, Mater. Sci. Eng., A, 2011, 528, p 6313-6323

11. L.G. Wang, B.F. Zhang, S.J. Zhu, C.X. Zhang, and S.K. Guan, Effects of Silicocalcium on Microstructure and Properties Of Mg-6A1-0.5Mn Alloy, Trans. Nonferrous Met. Soc. China, 2006, 16, p 551-555

12. G.Y. Yuan, Z.L. Liu, Q.D. Wang, and W.J. Ding, Microstructure Refinement of Mg-Al-Zn-Si Alloys, Mater. Lett., 2002, 56(1-2), p 5358

13. G. Yuan, M. Liu, W. Ding, and I. Akihisa, Microstructure and Mechanical Properties of Mg-Zn-Si-Based Alloys, Mater. Sci. Eng., A, 2003, 357, p 314-320

14. R. Walter and M.B. Kannan, Influence of Surface Roughness of the Corrosion Behavior of Magnesium Alloy, Mater. Des., 2011, 32, p 2350-2354

15. I.B. Singh, M. Singh, and S. Das, A Comparative Corrosion Behavior of Mg, AZ31 and AZ91 Alloys in $3.5 \% \mathrm{NaCl}$ Solution, J Magn Alloys, $2015,3(2)$, p $142-148$

16. R.B. Alvare, H.J. Martin, M.F. Horstemeyer, M.Q. Chandler, N. Williams, and P.T. Wang, Corrosion Relationships as a Function of Time and Surface Roughness on a Structural Ae44 Magnesium Alloy, Corros. Sci., 2010, 52, p 1635-1648

17. C.P. Kyung, H.K. Byeong, K. Hisamichi, H.P. Yong, and M.P. Ik, Microstructure and Corrosion Properties of Mg-xSn-5Al-1Zn (x¹/4 0, 1, 5 and 9 mass\%), Alloys Mater. Trans., 2010, 51(3), p 472-476

18. Y. Ma, J. Zhang, and M. Yang, Research on Microstructure and Alloy Phases of Am50 Magnesium Alloy, J Alloys Compd., 2009, 470, p 515-521 